\title{
Sustainable resources management in the context of agro-environmental EU policies: novel paradigms in Thessaly, Greece
}

\author{
E. Koutseris \\ Department of Planning and Regional Development, \\ University of Thessaly, Volos, Greece
}

\begin{abstract}
Primarily, this is a discussion and review of the general European policies of management protection in the perspectives of the new CAP (Common Agriculture Policy). There are some technical proposals in Thessaly for agriculture and environmental management with the contribution of a voluntary group such as the Working Team "Natural environment" (WTNE) in Natura 2000 and SPA (Special Protection Areas) by following a strategic PLAN. The fundamental problem and concept that this article examines is if the sustainable confrontation or approach can be better improved via means of the effectiveness and the short-term "valorization / utilization" of natural resources or if solutions should be found or proposed via means of long-term "conservation" of resources. Consequently, the completion of works, as paradigm, of 'Karla' reservoir dam's plain (collectors, water reservoir, etc.) and the beginning of projects for exploitation - valorization, created a reflection in regard to the type and manner of water consumption and the more general development and the valorization of level areas in Thessaly, Greece. The choice between different sustainable management solutions, except the solely "economic effects", will be supposed to include the parameter "environment" and it approaches the question of "exploitation - valorization" of resources in a context of effectiveness and "conservation" of resources.

Keywords: environmental EU policies, sustainable development, natural resources "valorization / utilization" versus "conservation", regions of ecodevelopment or controlled activities area.
\end{abstract}




\section{Introduction}

The most important measures for the environment were taken in the European Community, with the Single European Act in 1987 and the treaty on the EU in 1992. They addressed important environmental problems caused particularly by modern agriculture $[1,2]$. At the same time, two new protection issues arose: The network "Natura 2000", SPA and the management arose for Greece and Thessaly of water [3, 4]. In the EEC in 1992 an important step was made towards "sustainable development", the object of which is not only the protection of the environment but also sustainable future development. A new policy, focusing on preventive action, placed particular emphasis on the more rational use of resources, as well as on the reduction and the more effective use of the products, themselves [5-7].

"The new policy for rural space encouraged planning for the comprehensive development of the environment. Financial incentives were established in the form of various policies, which were aligned with the objectives of 'Natura 2000 - SPA' and would be able to contribute to its success". In this way, safeguards were placed on the areas where the certain types of EC Habitat and species of flora and fauna are found, while at the same time taking into consideration economic, social and regional requirements [8-10].

With the reform of CAP 1992, traditional developmental objectives were enriched with three new horizontal objectives, incorporating the environmental objectives into the CAP (Regulation 2078/92 and Reg. 2092/91): (a) the protection of environment, (b) the protection of human health and (c) the rational and viable exploitation of natural resources [3, 11, 12].

Regulation 1257/99 and the new CAP 2003 further promote the environmental regard in the rural sector connecting the issuing of aid with the observation of rules "equitable agricultural practice". This concerns mainly: the protection of waters, the controls in the use of fertilizers and pesticides, the protection of regions "Natura 2000" and the incorporation of environmental methods of production in the quality of products $[3,6,9,10,13]$.

In this context, two new plans, as paradigms, must be harmonized with the previously mentioned provisions for the agricultural development aiming at the same time to protect the environment. This approach forms the future of sustainable development in agriculture concerning: a paradigm for hydroenvironmental planning (management of water resources) and sustainable development in Thessaly and a novel control policy paradigm of sustainable management in Thessaly (eco-development of Natura 2000 plain-mountainous area). It will be supposed is given particular weight in the more rational use of resources, aiming at the reduction of environmental impacts and more effective use of produced products [7, 10, 12, 13].

The Author as Scientific in charge of Working Team WTNE, approaching the aspect of natural resources from the sustainability point of view, of these regions he attempt to contribute first in proposals concerning the minimisation of intensiveness of the flat regions under examination and afterwards in proposals 
concerning the appointment, projection and in general exploitation of mountainous regions to be contribute $[7,10,11,13,14]$.

\section{New regional agro-environmental policies, proposed by a voluntary group in Thessaly, Greece face to the new CAP}

Two important regional programs, from EU policies, Greece following. The first 'Natura 2000' Program covered three phases in Greece: Phase A (1992-1995), during which the inventory and evaluation of regions was accomplished; Phase B (up to 1998), during which a list of regions of community importance was created; and Phase C (up to July 2004), during which the 'Special Areas of Maintenance' were to be officially delimited and classified as habitat areas and the priorities for their conservation and the rehabilitation determined. In addition, 'regions of special protection' (SPA), contained in the Natura 2000, list was delimited, though these areas were focused on the protection of birds, based on Directive 79/409/EEC [14, 15]. The second program of the EU, the 'Corine Biotopes Project', led to the recording of the most important biotopes in Greece $[6,10,13-15]$.

Unfortunately, however, the expected consultations with local communities on the terms and the restrictions of 'Natura 2000' did not take place, when the first (scientific) list was drawn up in 1995. In many cases, lines had already been drawn on the map without due consideration of local needs and insights $[11,6$, $14,10]$. The extent of the regions covered by "Natura 2000" in the region of Thessaly is roughly $220,000 \mathrm{H} \alpha$ (percentage 16-20\%). As is apparent there are several regions of ecological interest that have been studied or are being studied. The creation of a European ecological network of special zones which will be named "Natura 2000" is anticipated for these regions. Those, according to the criteria of the 92/43 directive were classified by the Greek Centre of Biotopes Wetland in three categories of A., B., and C., significance [3, 6, 14].

During 2003 and 2004, the Working Team tried to cover the current lack of briefing and consciousness-raising through multiple meetings both in the capital of Thessaly, Larissa, and in 15 regions of special interest to environmental planning. Simultaneously, e-mails concerning general and specific proposals on environmental issues were sent to various institutions and to all the municipalities of Thessaly $[4,6,7,10,11,13,14]$.

Apart from briefing-informing, the goal of the Working Team was also the determine the activities within the framework of the 'Strategic Regional and Environmental Planning for the Sustainable Development of Thessaly' (PLAN) for the "Natura 2000" regions and for the aquatic resources of Thessaly. Planning focused more on the sectors that have an impact on the natural environment, while keeping in mind all of the diagnoses and regional policies, the Land-Planning Plan (LP/P), and the policies for rural space regarding the management of water and soil, as well as urban planning in rural areas $[10,11]$.

The proposed PLAN was not an end in itself, but a means for the intensification and future guarantee of development. This however must be supported by theories of sustainability. A general objective is that the 
development and the protection of the natural, social and cultural environment should become coordinated, so that, over time, the greatest possible economic profits for the region would be achieved. In other words, the main objective of the plan must be the minimization of negative impacts along with a parallel maximisation of advantages for the local economy, society and environment [7, $10,13,14]$.

Priorities of the measures and actions of the 3rd Community Structural Funds (CSF) of Thessaly were the promotion of "regions of natural beauty" and their integration into the "Natura 2000" network, to also include sensitive ecosystems and biotopes along rivers, lakes and coastal regions that were not included before. This is to be accomplished through the development and implementation of studies and rehabilitation of these regions, the promotion and management of their landscapes, the encouragement of visitors through the creation of centers and kiosks for Information and Environmental Education, the publication of briefing materials, the mapping out and organizing of paths and of other activities, sign-posting, fencing and land use planning, and the promotion of products of the 'Natura 2000' regions [10, 13-16].

Certain new EU policies have been presented in the so-called Agro-foodstuff Sector and Globalization: This labeling of organic and environmentally friendly products would take place under the auspices of the certification systems organized by ISO 14000 and EMAS (Environmental Management and Audit Scheme), as well as POP, E, CE - HACCP, which would insure competitive advantages in the international market for quality products and processes [4].

Taking into consideration developments and tendencies in the WTO, EU regulation 1257/99 and the new intermediary revision of CAP 2003 promote environmental considerations in the rural sector even more, connecting the provision of aid with adherence to the rules of 'equitable agricultural practice' which mainly concern: the protection of water, controls in the use of nitrate fertilizers and of pesticides, the protection of the 'Natura 2000' regions and of habitats, and the incorporation of environmentally friendly methods of production into the quality of products $[10,12]$.

But this would require a reorientation in EU spending in favor of viable laborintensive agriculture and know-how, which is at the same time environmentally friendly. In addition, there must also be a drastic reinforcement of laws concerning the commercial labeling of quality products, promotion of institutions for interdisciplinary and inter-professional regional collaboration and programs for the environmental consciousness-raising of consumers [14, 17].

However, all this would require the strategic reformation and reconstruction of the European agricultural model from individual production to a more qualitative, i.e., more collective and environmentally friendly system of production and consumption, all of which would require an increase in EU funding $[7,10,13,14]$.

The new CAP (June 2003 and April 2004) takes into consideration both the consumer and tax payer-citizen, while at the same time, giving European farmers the capacity to produce whatever the market demands. In the future, financial aid to agriculture will be given in part irrespective of the volume and type of 
production. In order to avoid the abandonment of production, member states can retain certain types of aid under specific conditions $[11,10,13,14,18]$.

\section{One paradigm for hydro-environmental planning and sustainable development in Thessaly}

The above project PLAN constitutes an important contribution in the environmental planning based on the network of regions of protection, conservation (maintenance) "NATURA", 'SPA' and the water resources management (Directive 2000/60 EU) in the new prospect of rural space. This project was drawn up by the Working Team "WTNE" of the region of Thessaly within the Program of local events of raising the awareness of the rural population in three phases. Phases A and B of PLAN were completed in 2004. Simultaneously, it constitutes (a) an evaluation of the participation in the Phase $\mathrm{C}$ of a Plan for Thessaly, (b) an evaluation with the title "Environmental social consensus in Thessaly", (c) an ex-post evaluation of acceptance and impacts of the application of the "Natura 2000" - "SPA" regions and management of aquatic resources, in the new prospect of rural space', which is briefly presented here, was recently published in the form of a Monograph. It constitutes the conclusions of all the activity of WTNE, in the form of the composition and synopsis of the Environmental Strategic Planning mentioned above [6, 10, 11, 13, 14, 18]. From the analysis PLAN the need of a 'New Strategic Management Natural and Water Resources and Work of Thessaly' results, which will include the following priorities from the special occasions of the PLAN.

A. Priorities in the water management until the year $2010[10,11,13,14]$ :

$1^{\text {st }}$ Sufficient and Qualitative Water supply of urban centers and settlements of Thessalian countryside by "Institution of Management of Waters Thessaly"

$2^{\text {nd }}$ Guarantee of Minimal necessary Environmental Benefit for Viability in the natural system of Pineios river and its tributaries by "Barrier in the extension of Private Drillings and in the over pumping of underground waters" and substitution of $>1000$ millions of $\mathrm{m}^{3}$ of underground reserves of over pumping in the period 1985-2000.

$3^{\text {rd }}$ Maintenance of viability of Rural Exploitations.

The means for above reported are:

* The water management as collective natural and social resource in insufficiency.

* Support of planning and subsidy of action of substitution in regions of mono-culture of cotton with subsidized not irrigated cultures.

* Restriction of mono-cultures, and reduction of $10 \%$ and increase only livestock-farming which does not overload the environment.

* Use of veterinary surgeon flows and the exploitation of organic fertilizers in replacement of chemists, the creation of model veterinary surgeon settlements, the biological Agriculture and the extension of regulation 1257/99 (2078/92) EU. 
* Proportional changes are included in regulation $1257 / 99$ on the creation and operation irrigatory and land reclamation work in the frames of 3rd CSF. The integration of each irrigatory project will be supposed to observe measurable criteria and certain beginnings that were cited already.

\section{B. Intervention for the creation of work of storage of surface waters}

As fundamental region of action of PLAN entire the Region Thessaly is considered. The PLAN forecasts the concretisation of two pilot drawings and the further choice of certain regions of action. This because its application in a relatively big region is a particularly awkward undertaking and so that are achieved concrete results which both they will contribute in the improvement of prevailing situation and they will function positively in its distribution. These regions, which can have geographic or thematic determination and content, will be offered for tourist and sustainable development and consequently they correspond in the criteria that were formulated. In the base of this aspect as regions of action they are selected.

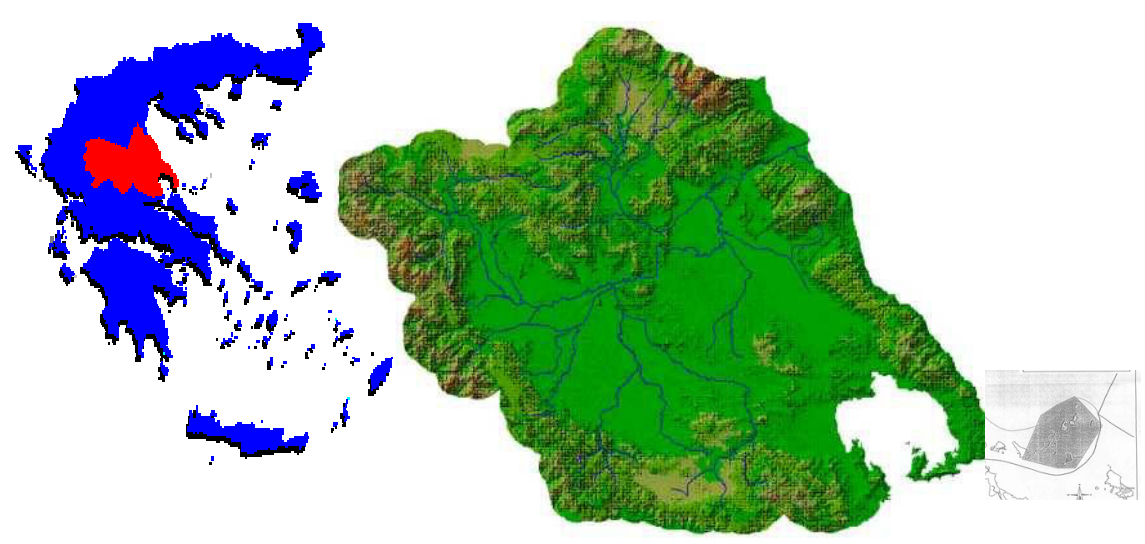

Figure 1: Region of Thessaly, Greece and Pineios river basin, with the Natura 2000 and SPA islands (Total surface area: $10.550 \mathrm{~km}^{2}$ ). Source: $[13,19]$.

Adversative places of prospect of development were presented in WTNE laboratory, which are influenced immediately by the political CAP. Concisely, the new proposals of the PLAN are as follows:

1. Sustainable tourist development in Thessaly. 2. Sustainable hydroenviromental development. 3. A hierarchy of environmental planning within the Prefectures .4. Choice of the regions for action. 5. Relating regional action priorities to the strategy of the plan. 6. Zoning. 7. The need for a national zoning and energy policy $[11,13,14,17,18]$. 


\section{A novel control policy paradigm of sustainable management in Thessaly}

The region of Thessaly allocates a large variety of eco-hydrological reserve that covers on the one hand all the natural particularities of Greek space and on the other a large breadth of human activities. Particular gravity was given by the Working Team of the Thessaly region, as model can be what is described in the above monograph the Eco-development region of "Karla - Mavrovouni Kefalovriso", as a controlled development area and the installed Committee of Management, which region is located in the south - eastern part of Thessaly [11, $17,20,21]$.

This was characterized, via Special Environmental Study (SES) and according to the articles 18 par 3 and 19 par. 2 and par. 5 of Greek National Low 1650 / 1986 as region of Eco - development Region (or pSCI, [4, 21]). The above also applies for other regions within the framework of Directive 92/43/EEC, which have been evaluated as essential for their integration into the Natura 2000 network. These areas have also been presented by the appropriate authorities to the European Committee, along with Regions of Special Protection (REP), as "proposed Regions CC" (pRCC), which will constitute the Network Nature 2000 (or pSCI), $[21,4]$. The regions listed below include all the above characteristics and are included under the Ministry of the Environment and Public Works plan [22]:

A) Mount Mavrovouni and the marine region surrounding it, which has been included in the European network of the protected region "Natura 2000" (see Figure 2, A and B in $[13,14])$.

B) The region affected by the work of re-creating Lake Karla which consists of the region of the re-flooding of the lake and the immediately adjacent region (Figure 2, B in $[13,14]$ ).

C) The wider region, flat and hilly, which is directly connected to the lake and constitutes its drainage basin (Figure 2, $\Gamma$ in $[13,14]$ ).

For the completed and effective protection and conservation of itself and its values it was separated in individual areas. These concern extensive regions that include villages or settlements that present on one side, problems of intensive agriculture and de-valorization, so that protection is required and on the other side, particular value and interest because of ecological geomorphologic, biological, scientific importance that require maintenance $[4,13,14]$.

The proposed new policies are related with the observed lack of regulations for certain questions that concern mainly the improvement of management of natural resources. This lacks in the sector of maintenance (or even reduction) the levels of consumed natural resources (energy or other) concern (a) regulations in local level for the important repercussions of environment, (b) regulations for the under protection regions, (c) regulations on restriction of consumption of energy (electric and humid fuels) and natural resources, (d) recycling and re-use of waste, (e) recording of levels of pollutants, (f) water management in the total of region or even in the wider Thessaly region and (g) systematic follow-up of habitat and not enacted interventions in cases of problems [7, 14]. 


\section{New proposals of sustainable resources management in Thessaly, Greece and conclusions}

The result of the rational management the surface and underground waters imposes the restriction of use of underground waters and the exploitation of surface waters of Karla area. This choice coincides with the general environmental choices of EU and strength then the economic development of region, which as mentioned before, presents economic and social degradation.

We approaches the question of "exploitation - valorization" of resources in a context of effectiveness and "conservation" of resources. The new European policies incorporate the environmental policies in the economic development and concern more the development of territorial entities despite the development of a sector of economy, such as agriculture. The "regions of controlled activities" - with one extension of protected regions and one reformation of cultivation land - are promoted, simultaneously with the national policy and the protected areas "Natura 2000, SPA", which in certain cases concern mainly level regions. The new rural and environmental rules, which are imposed parallel by the new CAP, lead to this direction more and more $[7,10,14]$.

In this context, the article deals with the development of the above work taking into consideration the new policies, it categorizes and rates the environmental problems territorial and quantitative and proposes rules. The article shapes on the one hand proposals for non-intensive exploitation of examined level areas, and on the other hand, proposals of appointment, projection and in general exploitation of the mountainous areas. All these are examined in a context of sustainable development of natural resources of these regions. These opposite opinions, with regard to the prospect of development of rural regions, were formulated in recent meeting that the Authorities of the region of Thessaly organized, where relative proposals for sustainable development of the Thessaly were proposed [14].

From the first part of the PLAN [11, 13] or the monograph [6], mentioned before, the results are: under the title 'Conclusions from the Evaluation' we pointed out the main problems that must be faced in Eastern Thessaly. These include: the management of solid waste, the intense problem of overexploitation of water resources, the need for controlled development of expanding settlements in the Eco-development regions, human intervention in nature, and the need for partial zoning and regulating of areas under intense use from human activity.

In Chapter Four, 'Examination of Methodology', certain conclusions were reached. These referred to principles on the general direction of PLAN, based on the ecological reserves, which led to two plans for the PLAN, including a new strategy for managing natural and aquatic resources, as well as construction projects and regulations in Thessaly, such as water supply for cities, restrictions on drillings, alternate sources for thousands of cubic metres of water, maintenance of the viability of agricultural production, and, finally, the creation of an Institute for the Management of Resources and the Environment in Thessaly. 
In Chapter Five under 'Final Conclusions - Priorities and Proposals', three general conclusions were reached. These referred to the need to establish priorities for the use of water up to the year 2010, interventions needed to regulate the demand, use and management of water, and planning for the creation of projects to collect surface waters. Finally, it was proposed that the number of areas and resources to be protected be increased [7, 10, 13, 14].

From Part Two seven proposals were made, relating to:

1. Sustainable tourist development in Thessaly

2. Sustainable hydro-enviromental development

3. A hierarchy of environmental planning within the Prefectures.

4. Choice of the regions for action.

5. Relating regional action priorities to the strategy of the plan.

6. Zoning

7. The need for a national zoning and energy policy

\section{References}

[1] A. Kungolos, P. Samaras, E. Koutseris. 2003, 'Using bioassays for testing seawater quality in Greece': In Journal of Environmental Science and Health, eds Marcel Dekker, Inc, Reprint Program, NY, Vol. A38, No. 533-544, 2003M

[2] Podimata, E. Koutseris and N. Tsiropoulos. 2004, 'Water Quality Assessment by Ecotoxicological and Chemical Methods in Magnesia, Greece': In Water, Air, and Soil Pollution: Focus, October 2004, vol. 4, iss. 4-5, pp 179-187 (9) Kluwer Academic Publisher

[3] Koutseris E.: 2003, General Directions of the Natura 2000-SPA regions and water resource management in Thessaly (dir.2000/60/EU): Management Committees and Regional - Agro- Environmental Measures in the New CAP',. In Newspaper 'Neos Tipos'. July, extensive publication, Volos

[4] Koutseris E.: 2003 a, 'General Directions of NATURA 2000-SPA regions and water resource management in Thessaly (dir.2000/60/EU): Management Committees and Regional - Agro- Environmental Measures in the New CAP': In Proceeding. 3rd Congress of the Development of Thessaly, ETHEM, Un. Thessaly, Technical Education Foundation (TEF), Larissa, 12-14/12/03, pp 375-393

[5] EU directive/92/43.: 1992, 'Natura 2000', «on habitats», EEEK, Brussels.

[6] Koutseris Ẽ 2004 a, Environmental social consensus in Thessaly: An ex post evaluation of the acceptance and impacts of the application of the 'Natura 2000 - SPA' regions, and water management resources, in the new prospect of rural space', Eds. Erodhios. Thessaliniki, p. 180 (in Greek)

[7] Koutseris E., Papavassiliou: 2005, 'Water as social and economic commodity: Efficacy or conservation sustainability methods'. In Conference Proceedings, EWRA69C. $6^{\text {th }}$ International Conference 710/9/05, Menton, France 
[8] Kotios A.: 2002, 'Restrictions and capacities of development activities in the 'Natura regions' in Conference Paper 26-4-02, dep. of P and RD, Un. Thessaly, Volos (in Greek)

[9] Koutseris E.: 2002, 'The integrated reconnaissance in environmental protection: A new approach to planning and design'. In Proceedings of the International Conference on 'Protection and Restoration of the Environment VI' (eds. A.G. Kungolos, A.B. Liakopoulos, G.P. Korfiatis, A.D. Koutsospyros, K.L. Katsifarakis, A.D. Demetracopoulos) Skiathos, pp. 1377- 84, July 1-5, 2002

[10] Koutseris E., Polysos S: 2005, 'Water resources exploitation-valorization in the context of environmental policies: The case of Smokovo's dam in Thessaly'. In Conference Proceedings, EWRA69A. $6^{\text {th }}$ International Conference 7-10/9/05, Menton, France

[11] Koutseris E. et al (Scientific in charge): 2004, Regional Environmental Strategic Plan of Sustainable Development of Thessaly (RESP of SD in Th): Based on the 'Natura' area and water researches management (dir. 2000/60/EU), WTNE of Region Thessaly, Larissa, p. 301 (in Greek)

[12] Koutseris E.: 2003 b, 'The new water policy: control and location of territory units with methodologies 'for a special or multiple impacts' in the small scale'. In Proceedings. $3^{\text {rd }}$ Congress of the Development of Thessaly, ETHEM, UTH, TEF, Larissa, 12-14/12/03, pp 269-291 (in Greek)

[13] Koutseris, E.: 2006, 'Application of E.U. Environmental Programs in Thessaly, Greece: Problems in management - protection', submitted in International Journal of sustainable development

[14] Koutseris E.: 2004 b, 'Agriculture ou Environnement? La région d'ex lac KARLA en Grèce', Discussion Paper Series, 10 (16): 407-438, Un. Thessaly, Volos

[15] Ministry of Greek Environment, EP.PE.R. 2001, 'Environmental Operational Programme', Internet, http://www.minenv.gr and http://www.minenv.gr/4/41/4108/g410801.html

[16] P.E.P.: 2000, Regional Operational Program of Thessaly 2000 - 2006, Special Management Service P.E.P., Larissa (in Greek)

[17] Koutseris E.: 2005 a, 'Methodologies of reconnaissance, with evaluation of environmental planning impacts and one new model of protection: For the protection or conservation'. In HELECO Symposium Proceedings for the technology of the Environment: In O-B 374 doc or abstract book: B 58: 71, TEE: HELECO '05, 3-6/2/2005, Athens

[18] Koutseris E.: 2004, 'Methodologies of reconnaissance and evaluation of the environmental planning impacts: for protection or conservation'. In EWRA Symposium Proceedings, on 'Water Resources Management: Risks and Challenges for the $21^{\text {st }}$ Century', Vol II, pp 903-914, Sept 2-4/9/04, Ismir, Turkey

[19] Panagopoulos A.; Evagelopoulos A.; Alexiou J.; Kalfountzos D. and Kotsopoulos S. (2001): Environmental Actions of Reg. 2078/92/EEC - 
State of Art Knowledge of Water Resources of river Pineios estuary, Thessaly, National Agricultural Research Foundation, Athens, 2001

[20] Koutseris E.: 2005 b, 'Climate and two-type torrential physiography: New Interdisciplinary Approaches and Discussion of Processes from Mediterranean Environmental Planning'. In Conference Proceedings, EWRA69B. $6^{\text {th }}$ International Conference 7-10/9/05, Menton, France

[21] ETHIAGE: 2000, Special Environmental Study and plan of management. ETHIAGE, Special Protection Area of mount Mavrovouni of the LIFE program (in Greek)

[22] Ministry of Greek Environment (Y.PE.HO.DE.): 2002, Special Environmental Study, Conclusions of Dep. of Natural Environmental Management (in Greek) 